\title{
Gone fishing: Looking to catch some answers for differing mortality in the CoreValve High-Risk Trial
}

\author{
Arman Kilic, MD, and Pavan Atluri, MD
}

\author{
From the Division of Cardiovascular Surgery, Hospital of the University of Pennsylvania, Philadelphia, Pa. \\ Disclosures: Authors have nothing to disclose with regard to commercial support. \\ Received for publication Dec 27, 2016; accepted for publication Jan 5, 2017; available ahead of print Feb 24, \\ 2017 \\ Address for reprints: Pavan Atluri, MD, Division of Cardiovascular Surgery, Hospital of the University of \\ Pennsylvania, 3400 Spruce St, 6 Silverstein Pavilion, Philadelphia, PA (E-mail: Pavan.Atluri@uphs.upenn.edu). \\ J Thorac Cardiovasc Surg 2017;153:1302 \\ $0022-5223 / \$ 36.00$ \\ Copyright (c) 2017 by The American Association for Thoracic Surgery \\ http://dx.doi.org/10.1016/j.jtcvs.2017.01.023
}

In this issue of the Journal, Gaudiani and colleagues ${ }^{1}$ present an in-depth analysis of the causes of mortality in the CoreValve U.S. Pivotal High-Risk Trial comparing transcatheter aortic valve replacement (TAVR) versus surgical aortic valve replacement $(\mathrm{SAVR}) .^{2}$ Death rates within 30 days and between 4 months to 1 year after the procedure were similar between TAVR and SAVR. The distributions of causes of mortality during these time points were somewhat expected. Moreover, early deaths in the TAVR cohort were related mainly to technical issues, with most requiring a second procedure, requiring valve retrieval, requiring conversion to open surgery, or having moderate or severe paravalvular leak. In the SAVR group, most early deaths were related to major surgical complications leading to cardiogenic shock or multiorgan failure. In the late phase occurring after 4 months, most deaths in both groups were unrelated to the aortic valve procedure, again as expected.

The provocative finding in this analysis is that deaths occurring within 1 to 4 months were observed at a higher rate in the SAVR cohort. Interestingly, 6 of the 27 SAVR deaths in this timeframe were from infection or sepsis. SAVR carries a higher operative burden and likely subjects the patient to higher infection risk in part because of more nutritional depletion and deconditioning, with a resulting detriment to normal immune function. This is particularly true for those surgical patients who have complications develop and have prolonged stays in the intensive care unit. In addition to their increased susceptibility, there are likely more avenues for nosocomial infection and transmission because they are in a higher risk environment for longer periods.

Perhaps a more alarming finding was that 5 of the 27 SAVR deaths in the 1 to $4-$ month time frame were related to patientprosthesis mismatch. Each of these 5 patients had a $19-\mathrm{mm}$ or 21-mm valve implanted, and all but 1 had moderate or severe patient-prosthesis mismatch at follow-up. There are several operative techniques, such as aortic root enlargement (eg, Nicks or Manougian procedures) or aortic root replacement, that can be used to avoid patient-prosthesis mismatch. It is

\section{References}

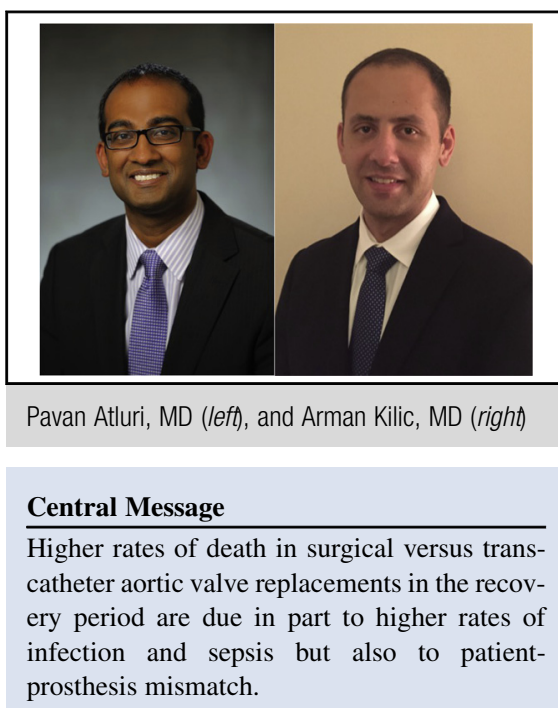

See Article page 1293 .

unclear whether these were used in these cases involving a small aortic annulus. Interestingly, if we eliminate these 5 cases in which the aortic stenosis was inadequately treated surgically, the mortalities are comparable between TAVR and SAVR between 1 and 4 months $\left(P=.18\right.$ by $\left.\chi^{2}\right)$.

Although these factors were outside the scope of this study, the durability of the valve and freedom from reintervention in the longer term will continue to be essential points when comparing TAVR and SAVR. ${ }^{3}$ The importance of these factors will likely vary across the spectrum of surgical risk. In patients who are at high operative risk and have limited life expectancy, valve durability will likely be of less relative consequence than successful hospital discharge. In contrast, durability of the valve and freedom from reintervention will play a larger role in patients at low surgical risk with longer life expectancies. Trials and analyses like this one will continue to shed more insight into patient selection and ways to improve outcomes for both therapies.

1. Gaudiani V, Deeb GM, Popma JJ, Adams DH, Gleason TG, Conte JV, et al. Causes of death from the randomized CoreValve US Pivotal High-Risk Trial. J Thorac Cardiovasc Surg. 2017; 153:1293-301.e1.

2. Adams DH, Popma JJ, Reardon MJ, Yakubov SJ, Coselli JS, Deeb M, et al; U.S. CoreValve Clinical Investigators. Transcatheter aortic-valve replacement with a self-expanding prosthesis. N Engl J Med. 2014;370:1790-8.

3. Vahl TP, Kodali SK, Leon MB. Transcatheter aortic valve replacement 2016: a modernday "Through the Looking-Glass" adventure. J Am Coll Cardiol. 2016;67:1472-87. 